\title{
Qué escuela, para qué inmigrantes. Zonas de procedencia y tipos de escolarización: el caso de Canarias
}

\author{
Begoña M. Zamora Fortuny \\ Universidad de La Laguna. Departamento de Sociología \\ bezamora@ull.es
}

\section{Resumen}

La distribución de los inmigrantes en el sistema educativo muestra una realidad muy distinta en la geografía española. Las grandes características diferenciadoras serán las que dirijan el desarrollo de este trabajo, haciendo especial referencia en el análisis comparativo al archipiélago canario. No sólo la comunidad autónoma de acogida, sino también la zona de procedencia de los inmigrantes se convierten en elementos esenciales para entender la distribución según niveles educativos y titularidad de los centros. El análisis de esta cuestión y su comparación con el alumnado autóctono nos permitirá distinguir hasta dónde llega la búsqueda de igualdad o de diferencia de los inmigrantes y destacar cuáles son las comunidades autónomas más igualitarias. Asimismo, se cuestionará el sentido de algunas de las políticas y de las prácticas educativas.

Palabras clave: inmigración, zona de procedencia, sistema educativo, titularidad de los centros, niveles educativos, reproducción social, comunidad autónoma, Canarias.

Abstract. What school for what immigrants. Country of origin and types of education: the case of Canary Islands

The data on immigrants in the educational system show us a very different reality in the Spanish geography. The great differentiating characteristics will guide the development of this article, doing special reference to Canary Archipelago in the comparative analysis. Autonomous Community of reception and zone of origin of immigrants are essential elements to understand the distribution according to the educational levels and according to ownership, public or private, of the educative centres. This analysis and its comparison with native students will allow us to distinguish if immigrants search equality or difference in schools. Besides, will stand out which autonomous communities are more egalitarians. Some educative political and practices will be questioned.

Key words: immigration, zone of origin, educational system, ownership of centres, educational levels, social reproduction, autonomous community, Canary Islands. 


\section{Sumario}

Como punto de partida

Perfil del alumnado inmigrante. Un alumnado inmigrante heterogéneo en una España diversa

Alumnado extranjero en educación postobligatoria. Una elección marcada por la zona de procedencia
Distribución del alumnado extranjero según la titularidad de los centros. La privatización de la diferencia Alumnado inmigrante y autóctono en centros privados. El peso de la reproducción social

Bibliografía

\section{Como punto de partida}

No parece que la legislación educativa tenga una sensibilidad adecuada hacia la realidad diversa de la inmigración, ya que circunscribe la «atención educativa al alumnado inmigrante y perteneciente a minorías étnicas o culturales» (Gobierno de Canarias, 2005: artículo 46) a las necesidades educativas específicas (NEE). Para empezar, porque el alumnado inmigrante de grupos sociales desfavorecidos es minoritario en el archipiélago, pero, además, porque no pueden generalizarse tales NEE para toda la inmigración, puesto que únicamente puede ser incluida en un colectivo único desde el desconocimiento o, peor, desde la ligereza y el oportunismo (Carabaña, 2004; Hernández i Dobon, 2004; Zamora, 2003). La consecuencia automática de estas concepciones en política educativa es la estigmatización de los inmigrantes, con lo que se contribuye a ampliar y consolidar la imagen distorsionada que de los mismos difunden los medios de comunicación (Zamora, 2004).

Más aún, bajo la retórica de la educación intercultural y de la educación para la tolerancia, se ocultan, a veces, relaciones de dominación y conflictos entre inmigrantes y autóctonos (Carbonell, 2005: 30) y entre distintos grupos de inmigrantes, de lo que resulta más la legitimación de diferencias sociales, que la profundización de la igualdad de oportunidades para conseguir que, en los resultados y en la promoción en el sistema educativo, esté cada vez menos presente la relación con la condición social de partida del alumnado. Luego, lo que parece estar ocurriendo es que también con los inmigrantes la tendencia a la reproducción social en el sistema educativo es consistente: existe una importante relación entre el perfil educativo y profesional de los padres del alumnado inmigrante y la educación que reciben sus hijos, el tipo de centro en el que son escolarizados, la permanencia, la promoción y las elecciones educativas postobligatorias, y, en fin, en algunos casos, hasta en el tener una educación que es una extensión mimética de la de sus países de origen.

En Canarias, la construcción social de la condición de inmigrante gira alrededor de las personas y de los colectivos procedentes de África o de América del Sur - aun cuando, en este último caso, no existan diferencias idiomáticas decisivas con la población local-, y se olvidan los importantes contingentes migratorios llegados de la Europa «rica» (Baráibar, 2005: 31). 
De esta manera, algunos colectivos de inmigrantes logran imponer sus demandas de defensa de su especificidad cultural, con el argumento de no sufrir discriminación identitaria, mediante la creación de escuelas privadas y privadas concertadas para mantener la diferenciación social y/o religiosa (Azurmendi, 2003: 30). Otros, sin embargo, dado su escaso poder económico y social, terminan accediendo a los centros públicos más devaluados, compartiendo su destino con los estratos más bajos de la población local y adaptándose «naturalmente» a las políticas educativas diseñadas para ellos: los programas de garantía social y «una oferta de FP, que coadyuve al crecimiento", aun cuando, desde la Administración, ello se justifique como una medida que permite «acoger en condiciones de igualdad» con el alumnado de Canarias al alumnado recientemente llegado al sur de las islas (Gobierno de Canarias, 2001).

El objetivo de este trabajo, pues, es arrojar alguna luz sobre las confusiones y los ocultamientos que venimos comentando. Con ese propósito, nos centraremos en las grandes diferencias de escolarización, de tipo de centro educativo y de éxito académico, según la condición social y la procedencia de los inmigrantes. De paso, denunciaremos la vinculación que tiende a establecerse entre inmigrantes, problemas educativos y fracaso escolar.

Podríamos decir que, del mismo modo que las expectativas previas y los «etiquetajes» de los profesores influyen en los resultados educativos de los alumnos, también ocurre algo similar con la percepción y la valoración que hacen los docentes en términos culturales. El convencimiento por parte de los enseñantes de que la cultura de determinados colectivos de alumnos es muy diferente a la hegemónica, conduce frecuentemente a que también se considere peor, lo que deriva en malos resultados académicos y en la confirmación de que son peores estudiantes que, si acaso, podrían acceder a la formación profesional, pero nunca a la rama académica del sistema educativo. Como dice Terrén (2001: 90), en las relaciones étnicas, el profesor se sitúa del lado del poder cultural del grupo dominante, lo que le lleva a distinguir jerárquicamente al alumnado según sus percepciones culturales. Una actitud que, pese a ser producto de imágenes distorsionadas, está legítimamente amparada social e institucionalmente ${ }^{1}$.

Como es conocido, el fracaso escolar es mayor en los hijos de determinadas familias de inmigrantes (Fullana-Besalú-Vila, 2003: 23) y aunque no existe unanimidad sobre los factores que explican las diferencias de rendimiento (Defensor del Pueblo, 2003b: 9), el aspecto más señalado es el dominio de la

1. Y a veces sin necesidad de legitimación o con una legitimación más que forzada, como parece haber ocurrido en Holanda, donde se encamina al alumnado inmigrante, marroquí y turco, a formación profesional, a pesar de terminar con éxito la escuela primaria. El argumento esgrimido: el «temor de los maestros a que los alumnos abandonen una secundaria difícil». Y, como refleja el informe que ha desvelado estos resultados, estaría pesando mucho más la percepción que los docentes tienen del alumnado y el entorno social de éstos, que las calificaciones (El País, 22/2/2002). 
lengua del país de acogida (OCDE, 2002: 27, citado en Navarro-Huguet). Sin embargo, las competencias lingüísticas y comunicativas necesarias para triunfar en el sistema educativo se inscriben en códigos sociolingüísticos y, como planteaba Bernstein (1989), corresponden a universos de sentidos propios de las diferentes clases sociales. Es probable que esto ayude a explicar las diferencias de resultados educativos de los inmigrantes según la disímil condición social que se deriva de sus procedencias. Así, por ejemplo, que el sistema educativo español valore el manejo del inglés, del francés y del alemán, facilita mucho las cosas a quienes unen al hecho de tener esas lenguas de "cuna» una posición económica y sociocultural media-alta en la sociedad ${ }^{2}$. Entonces, si, como ocurre en la población autóctona, las variables socioculturales son las más consistentes para entender el tipo de escolarización y el éxito o el fracaso del alumnado (Colectivo IOÉ, 2003: 161), tienden a desaparecer las diferencias de rendimiento entre el alumnado inmigrante y el autóctono que no sean debidas a la situación sociocultural (Navarro-Huguet, 2005: 65; Defensor del Pueblo, 2003b: 11).

En consecuencia, cuando se asocia el tipo de centro con el éxito o el fracaso escolar de los inmigrantes, según sean privados o públicos, de lo que se está hablando en realidad es del estatus social, profesional, académico de las familias del alumnado inmigrante que va a cada centro. Pero la solución no parece pasar por la distribución del alumnado entre centros públicos y privados como medida que propiciaría la igualdad de oportunidades del alumnado inmigrante con el autóctono, por varios motivos, entre otros, porque la marginación no desaparece por enviar al alumnado marginado a centros privados, porque sería un agravio comparativo con el alumnado autóctono, y porque una parte importante del alumnado inmigrante, en Canarias, ya está en los centros privados. Aunque sea un argumento menor, algunos aducen además que se coartaría la libertad en la elección de centro (Carabaña, 2006: 34; Fernández Enguita, 2003: 48). De ahí que no resulte extraño el escaso éxito que han tenido las iniciativas destinadas a favorecer la redistribución artificial del alumnado inmigrante para evitar su concentración excesiva en determinados centros. Incluso se podría añadir a lo dicho que tal vez las familias de inmigrantes tienden a preferir la concentración escolar que supone mayor seguridad y comodidad (Carbonell, 2005: 44) y muy probablemente porque la guetización social y geográfica ya está hecha y el habitus sobre la importancia de la escuela como motor de movilidad social, construido.

Aun cuando el objetivo de este trabajo es, en parte, conocer mejor las culturas de clase de los inmigrantes, somos conscientes del valor relativo de un indicador como es el de la agrupación de nacionalidades, que, en principio, pueden mantener una relación cultural particular respecto a la cultura esco-

2. Es más que ilustrativo el análisis de Terrén sobre la actitud complaciente del profesorado hacia el alumnado asiático y de Europa del Este, por la capacidad de esfuerzo y disciplina de éstos y de la baja expectativa del profesor hacia el alumnado magrebí, que se alejaría del alumno modelo, a pesar de su rápido aprendizaje de la lengua (Terrén, 2001). 
lar. En todo caso, consideramos que, junto a los fines del sistema educativo, ello nos permitirá comprender mejor por qué el alumnado se distribuye de manera tan diferente según redes de escolarización y, sobre todo, a qué es debida la enorme desigualdad educativa, tanto entre inmigrantes como en la población autóctona, además de las diferencias por comunidades autónomas.

Ahora bien, son evidentes las dificultades que acompañan a estos propósitos, también derivadas de las fuentes disponibles. La importancia del fenómeno de la inmigración en el siglo XXI ha hecho que se actualicen datos y proliferen estudios sobre interculturalidad. El MEC, en los últimos años, publica los datos sobre el curso escolar, la región geográfica de procedencia, la comunidad autónoma, el nivel educativo, la titularidad del centro y el género del alumnado. Pero, aún así, ni la información ni los análisis son todo lo completos que deberían.

Contar con una mayor base estadística sobre el sistema educativo y con datos que desagregan la variable «zona de procedencia» agrupando a un conjunto de países, tiene la ventaja de aportar un abanico amplio, por comunidades autónomas y por provincias, estableciendo un análisis comparativo entre éstas, así como entre distintos grupos de inmigrantes en relación con el sistema educativo. Pero tiene limitaciones que no podemos pasar por alto. Por ejemplo, podemos distinguir las procedencias de los inmigrantes a los que se les asigna el calificativo de económicos, pero no podemos saber quiénes de los inmigrantes procedentes de una zona que responde a la categoría de económica, son realmente inmigrantes económicos.

Por otro lado, se sigue careciendo de un marco de referencia bien articulado, lo que hace difícil poder contribuir al conocimiento en la materia. Se echan en falta datos sólidos sobre las desigualdades de rendimiento (Terrén, 2005: 115-116) y un marco teórico consistente que acabe con el "mariposeo intelectual alrededor de la moda de la interculturalidad» (Carbonell, 1997: 26).

Aquí tampoco vamos a poder dar solución a los problemas planteados que requerirían de una investigación ex profeso, tanto teórica como de campo. Nos limitaremos, pues, a dar la información disponible y a la dependencia de los datos oficiales.

Hasta prácticamente la década de los noventa, no hay datos o son inconsistentes. La Estadística de la enseñanza en España, del MEC, en los primeros años, no diferencia entre el alumnado matriculado en centros públicos o privados, no cuenta, cuando tiene la información, con criterios homogéneos en el tratamiento de datos facilitados por las distintas consejerías educativas, y tampoco éstas con la información recibida de los centros, lo que afecta incluso a la definición de extranjero o a que la nacionalidad registrada no siempre se corresponda con la realidad (CIDE, 1999: 36) ${ }^{3}$.

3. En 1992 se publica el primer trabajo del MEC bajo el título de Informe sobre la educación intercultural en España, donde se estructura la información disponible sobre inmigración y educación, tanto en datos como en proyectos. Aunque el CIDE reconoce que el trabajo que publicara en 1999 sobre Las desigualdades de la educación en España II y el anterior de 
Entre las comunidades autónomas donde más destaca el fenómeno de la inmigración figuran Madrid, Cataluña, Comunidad Valenciana, Andalucía y Canarias. En esta última está más inexplorado el campo de estudio. Es la única de este grupo donde no se han realizado jornadas monográficas sobre inmigración y educación ni han proliferado estudios específicos sobre el tema. Incluso algunos de los trabajos nacionales recientes que desglosan su análisis por comunidades autónomas que cuentan con mayor inmigración, excluyen a Canarias ${ }^{4}$.

Más allá de los llamados «estudios interculturales» centrados en esta comunidad autónoma, entre ellos algunos generados por el Consejo Escolar de Canarias (2001), el único informe riguroso hecho en Canarias sobre inmigración y educación es el elaborado por el Instituto Canario de Evaluación y Calidad Educativa (ICEC): Bases para la realización de un proyecto sobre inmigración, escolarización y educación multicultural en Canarias (http://educa.rcanaria/es.icec), que los redactores consideran un documento preliminar, como refleja el propio título. Se trata de un documento de los más completos que alude al número de alumnos extranjeros, su distribución por islas, centros, tasas de alumnado por municipio, por isla, por nacionalidad, titularidad de los centros, niveles educativos y dominio idiomático, referido al curso 2002-2003.

Con las limitaciones expuestas, abordaremos el tema haciendo hincapié en la última década, la de mayor repercusión del fenómeno en Canarias, y centrándonos únicamente en los niveles educativos no universitarios, por cuestión de espacio y de interés socioeducativo.

\section{Perfil del alumnado inmigrante.}

\section{Un alumnado inmigrante heterogéneo en una España diversa}

Aunque el número de alumnos extranjeros en el sistema educativo español es escaso, tanto en el porcentaje que representa respecto del alumnado autóctono como en relación con la situación de los países vecinos de la Unión Europea y de EEUU, no ha parado de crecer en los últimos años. En educación no universitaria, entre 1991-1992 y 2004-2005 se ha multiplicado por más de $14 \mathrm{o}$, dicho de otra forma, ha aumentado en un $1.344 \%$, a la vez que disminuye el alumnado autóctono (entre 1991 y 2002 ha pasado

1992, son informes descriptivos que ofrecen estadísticas y valoraciones comparativas entre 1981-1990 y 1990-1997 sin análisis explicativos, los datos son más que escasos en el primer periodo. Y, aunque abundan más en el segundo momento, algunos trabajos de mediados de la década de los noventa seguían denunciando la falta de datos, bien por inexistentes o por falta de accesibilidad a los mismos. Así lo hacía el Colectivo IOE en 1996.

4. Los motivos son variados. A veces por escasear la información sobre el archipiélago, otras por la propia particularidad de la inmigración en Canarias. En este último caso, es ilustrativo el Informe del Defensor del Pueblo (2003), que analiza las comunidades de Madrid, Cataluña, Andalucía, Valencia y Murcia, y deja fuera a Baleares y Canarias. El argumento: que aun contando con un alumnado extranjero numeroso, éste no puede ser calificado totalmente como alumnado de origen inmigrante. Defensor del Pueblo (2003: III-IV). 
de 8,2 a 6,6 millones) (Colectivo IOE, 2003: 155). España ha pasado de tener 53.213 alumnos inmigrantes en 1994-1995 a tener cerca de 500.000 en 2005-2006. En cualquier caso, el ritmo de crecimiento del alumnado inmigrante se ha ralentizado 5 .

Podría hablarse, en España, de tres momentos atendiendo al lugar de procedencia del alumnado. Hasta el curso 1996-1997, predominan los procedentes de la Unión Europea (UE); a partir de 1997-1998, son mayoría los llegados de África, y desde el curso 2001-2002, tienen mayor presencia los venidos de América del Sur ${ }^{6}$, todo lo cual ha de entenderse no circunscrito a los continentes, sino a lo que suele denominarse oficialmente «área geográfica de nacionalidad ${ }^{7}$, porque de atender meramente al continente de procedencia, los africanos no tendrían ningún momento histórico en el que hubiesen destacado (ver tabla 1).

Pero la procedencia del alumnado inmigrante varía enormemente según las diversas comunidades autónomas. Mientras unas comunidades reciben mayor proporción de alumnado de la UE que de África, como Canarias (un 26,7 frente a un 8,9\%), Andalucía (un 31,6 frente a un 20,1\%), Valencia (un 19,4 frente a un 11,9\%) y Baleares (un 22,6 frente a un 17,4\%); en otras se da la situación contraria, como en Madrid (un 7,9 frente a un 13,8\%) o Cataluña (un 6,5 frente a un 31,7\%) (MEC, 2005).

La variación del alumnado inmigrante por comunidad autónoma también es notoria en la trayectoria seguida en el tiempo. En Canarias, en números absolutos, el alumnado inmigrante en educación no universitaria ha pasado de ocupar la sexta posición de las diecisiete comunidades autónomas más Ceuta y Melilla a principios de los noventa (1991-1992), a tener la cuarta prácticamente a lo largo de toda la década y la quinta en lo que llevamos transcurrido de siglo XXI. En números absolutos, supone pasar de 2.843 alumnos en 1991-1992 a 24.946 en 2004-2005, es decir, se ha multiplicado por casi nueve, ha aumentado en un $877 \%$ el número de alumnado extranjero (MEC, 2005c; CES, 2005: 179). En el archipiélago, la evolución seguida puede dividirse en dos momentos con tónicas distintas, hasta el curso 2000-2001, con tasas de crecimiento en Canarias superiores a la media española y, a partir de enton-

5. Se ha multiplicado por diez en la última década, pero ese crecimiento sigue un ritmo más lento en los últimos años, de tal forma que el crecimiento del curso 2002-2003 fue de 101.100; en 2003-2004, de 90.000; en 2004-2005, de 52.792, y en 2005-2006, de 50.000 (El País, 26-9-2005).

6. Por procedencias, en los últimos años destacan los que vienen de América del Sur y Central (48,7\%), básicamente de Ecuador y Colombia; de países europeos (26,4\%), sobre todo de Rumanía, y de África (19,1\%), mayormente de Marruecos (El Pais, 26-9- 2005: 26-9).

7. La zona de procedencia como área geográfica de nacionalidad es sin duda una arbitrariedad, pero que seguiremos en este estudio, dado que es la utilizada en las estadísticas oficiales. Se sintetizan en: Europa, distinguiéndose Unión Europea y resto de Europa (no siempre disgregada, lo que no ayuda mucho a realizar el análisis en detalle); América, dividida en norte, central y sur; Asia, Oceanía y África (en ocasiones también dividida en norte y resto). 
Tabla 1. Porcentaje de alumnado extranjero por área geográfica de procedencia

\begin{tabular}{|c|c|c|c|c|c|c|c|c|c|c|}
\hline & \multicolumn{5}{|c|}{ España } & \multicolumn{3}{|c|}{ Canarias } & \multicolumn{2}{|c|}{$\begin{array}{l}\text { Provincias } \\
52004-2005\end{array}$} \\
\hline & 1991-1992 & 1995-1996 & $1999-2000$ & 2003-2004 & 2004-2005 & $1999-2000$ & 2003-2004 & 2004-2005 & $\begin{array}{l}\text { Las } \\
\text { Palmas }\end{array}$ & $\begin{array}{l}\text { Santa Cruz } \\
\text { de Tenerife }\end{array}$ \\
\hline Europa & 45,6 & 39,5 & 33,8 & 24,9 & 26,3 & 50,0 & 31,2 & 30,9 & 28,2 & 34,2 \\
\hline Unión Europea $^{8}$ & 39,6 & 31,8 & 25,4 & 12,4 & 13,5 & 43,7 & 26,4 & 26,7 & 23,0 & 31,3 \\
\hline Resto de Europa & 6,0 & 7,7 & 8,3 & 12,5 & 12,8 & 6,3 & 4,8 & 4,2 & 5,2 & 2,9 \\
\hline África & 17,1 & 25,5 & 29,7 & 18,9 & 19,1 & 10,1 & 9,1 & 8,9 & 13,1 & 3,7 \\
\hline América del Norte & 4,2 & 3,5 & 2,2 & 1,2 & 1,1 & 0,7 & 0,9 & 4,0 & 0,9 & 0,8 \\
\hline América Central & 2,9 & 4,6 & 6,3 & 3,8 & 3,8 & 5,6 & 5,9 & 5,4 & 5,7 & 5,1 \\
\hline América del Sur & 21,4 & 17,9 & 19,6 & 46,5 & 44,8 & 19,7 & 45,3 & 46,2 & 42,5 & 50,8 \\
\hline Asia & 8,5 & 8,5 & 8,1 & 4,5 & 4,6 & 13,7 & 7,6 & 7,6 & 9,5 & 5,3 \\
\hline Oceanía & 0,3 & 0,2 & 0,1 & 0,1 & 0,0 & 0,2 & 0,0 & 0,0 & 0,0 & 0,1 \\
\hline No consta & 0,0 & 0,4 & 0,1 & 0,2 & 0,3 & 0,0 & 0,0 & 0,0 & 0,0 & 0,0 \\
\hline $\begin{array}{l}\text { Total }=100 \\
\text { (en miles) }\end{array}$ & 31.661 & 57.406 & 107.301 & 401.381 & 457.245 & 8.749 & 21.996 & 26.946 & 13.727 & 11.219 \\
\hline
\end{tabular}

Fuente: MEC (2005a) y elaboración propia con datos del CIDE (2003a). Curso 2003-2004 (CES, 2005: 182). Curso 1999-2000, 2004-2005 (MEC, 2005c).

ces, con tasas inferiores, aunque compartiendo un crecimiento mucho más acelerado con la media estatal (CES, 2005: 179).

El transcurso de esos años ha marcado una evolución muy distinta en Canarias por tipos de inmigrantes. Como puede verse en la tabla 1, han descendido los alumnos procedentes de la Unión Europea, en 17 puntos porcentuales, y han aumentado los llegados de América del Sur, en 27 puntos (MEC, 2005). En contra de lo que muchas veces se ha mantenido, la presencia de alumnado africano no ha aumentado en los últimos años en los centros educativos, pasando de representar el 10,1\% en el curso 1999-2000 al 8,9\% en el curso 2004-2005 y con un continuo aunque leve descenso entre esos años (Defensor del Pueblo, 2003: 33; CES, 2005: 182; MEC, 2005a). En este último curso académico, pueden verse otras grandes distancias entre el alumnado inmigrante que llega a España y el que llega a Canarias. Así, por ejemplo, mientras en el archipiélago se da una proporción similar entre alumnado africano y asiático, en España se multiplica por más de cuatro el alumnado africano frente al asiático. La mayor cantidad de alumnado europeo en comparación con la media estatal y la reducción a la mitad del africano, junto con una pre-

8. El crecimiento de europeos de la Unión Europea en el último curso se debe a que en esos momentos se incluyen los diez nuevos países miembros que figuraban en los cursos anteriores como procedentes del resto de Europa. 
sencia compartida importante y en aumento de latinoamericanos, permite hablar de una mayor proximidad con la cultura de acogida (Fernández Enguita, 2003: 244 y 247).

Como puede verse en la tabla anterior, las provincias canarias tienen una distribución del alumnado inmigrante particular. Así, aunque las dos primeras comunidades de inmigrantes con más peso son las mismas en ambas provincias, América del Sur y Unión Europea (que suman el 65,5\% del alumnado en Las Palmas y el 82,1\% en la de Santa Cruz de Tenerife), el tercer puesto en la provincia oriental lo ocupa África $(13,1 \%)$, colectivo éste que, en la provincia occidental, se traslada a la quinta posición, teniendo más presencia el alumnado procedente de Asia y América Central.

La distribución por provincias de los inmigrantes sigue una tónica similar a la del alumnado autóctono, aunque con un ligero peso sobre las islas orientales de los primeros, que suponen el 56,2\% frente al 53,6\% de autóctonos, siendo en las occidentales de $43,8 \%$ y $46,4 \%$, respectivamente. Pero esta diferencia se agranda si hablamos de islas, particularmente acusada en Lanzarote y Fuerteventura, que concentran el $7 \%$ y el $4 \%$, respectivamente, del alumnado total de Canarias y prácticamente el doble de los extranjeros, el 16\% y el $7 \%$. Lo contrario ocurre con Tenerife y Gran Canaria, que escolarizan al 83\% del alumnado total de Canarias y diez puntos menos del alumnado extranjero. Más llamativa aún es la situación por municipios. En 23 de ellos estudia el 86\% del alumnado extranjero; en 7, la mitad, y en sólo 2 (Las Palmas de Gran Canaria y Arona) vive 1 de cada 4 extranjeros que hay en Canarias (ICEC, 2005: 2, 4, 7).

Más significativo que el número de alumnos extranjeros matriculados es el número de éstos en relación al total de matriculados en educación no universitaria, situación que varía mucho según la comunidada autónoma y el período analizado. Se trata de una proporción bastante reducida, de 6,5\% en el curso 2004-2005, aunque no ha parado de aumentar en el conjunto de España, siendo de 0,7\% una década antes (1995-1996) (MEC, 2005a: series de alumnado extranjero $)^{9}$.

De cada cien alumnos, en cada una de las islas son extranjeros 13 en Lanzarote, 9 en Fuerteventura, 7 en El Hierro, 6 en La Gomera y en Tenerife y 5 en Gran Canaria y en La Palma. Si hacemos lo propio con los municipios,

9. Baleares $(11,1 \%)$ y Ceuta $(1,5 \%)$ son las comunidades más polarizadas. Canarias se sitúa por encima de la media $(7,1 \%)$, ocupando la novena posición, lejos quedan los porcentajes de 0,7 en 1994-1995 y 5,6 en 2003-2004 (MEC, 2005b, CES, 2005: 179).

Por niveles educativos, pueden verse algunas diferencias. Así, por ejemplo, en el curso 2000-2001, en educación obligatoria, había en España 21,5 alumnos extranjeros por cada mil matriculados, sobresaliendo las comunidades de Madrid (49,2), Baleares $(45,1)$ y Canarias (33,7) (CES, 2003:159). Tres cursos más tarde, atendiendo sólo a primaria, había en España 69,7 alumnos extranjeros por mil matriculados, ocupando Canarias $(73,3)$ la décima posición tras Madrid, Baleares, La Rioja, Navarra, Murcia, Cataluña, Valencia, Melilla y Aragón (CES, 2005:35), siempre por encima de la media en educación obligatoria. 
las diferencias son abrumadoras. Los casos más polarizados los encontramos en Tías en Lanzarote, donde el 26,9\% del alumnado allí escolarizado es extranjero, a mucha distancia de La Victoria de Acentejo en Tenerife y Hermigua en La Gomera, donde el 0,4\% del alumnado escolarizado es extranjero. Como puede verse en la tabla 2, con más de un $20 \%$, destacan también Mogán $(25,3)$ y Arona $(20,8)$; con más de un $15 \%$ : Adeje $(18,4)$, Yaiza $(15,8)$ y La Oliva $(15,7)$; y con más de un 10\%: Valle Gran Rey, Puntagorda, Pájara, San Bartolomé de Tirajana, San Miguel, Teguise, Alajeró, Antigua, Garafía, San Bartolomé, Arrecife, Santiago del Teide y Barlovento (ICEC, 2005: 8-9).

Hay una cosa clara que indican estos datos. No puede tratarse por igual el tema de la inmigración y la educación en Canarias que en el resto de comunidades, ni entre éstas, ni dentro del propio archipiélago, dada la heterogeneidad de los perfiles educativos del alumnado.

El perfil geográfico del alumnado extranjero en Canarias es el de un alumno americano (8.662), lo que supone casi la mitad del total, siendo mayormente hispanoamericanos ${ }^{10}$ de América Central y del Sur $(98,8 \%)$ - destacan colombianos (2.740), venezolanos (1.649), argentinos (1.384), cubanos (803), ecuatorianos (744) y uruguayos (359) - y de un alumnado europeo (5.932), en su mayoría de la UE (85\%) —-destacando Inglaterra (1.626) y Alemania (1.559) - Éste es básicamente el perfil del alumnado que engloba a 8 de cada 10 extranjeros, los otros dos lo forman un africano (1.704) y un asiático (1.522), predominando entre los primeros los marroquíes (2 de cada 3 ) y, entre los segundos, los indios y los chinos (el 75\%) (ICEC, 2005).

Es en las zonas turísticas, básicamente ubicadas en el sur de las Islas, donde se halla la mayoría de los inmigrantes. Pero el perfil cobra tintes distintos según provincias, islas y municipios. Así, por ejemplo, en las islas orientales se concentra más del $80 \%$ de africanos, del $70 \%$ de europeos extracomunitarios, del $60 \%$ de asiáticos y de la mitad de latinoamericanos. Mientras que las occidentales agrupan algo más de la mitad de europeos comunitarios.

En la tabla 2 se recogen las procedencias del alumnado extranjero en los municipios donde es mayor su presencia en relación con el autóctono, quedando constancia de la gran dispersión y variación de la inmigración educativa en islas y municipios.

Con más de diez alumnos extranjeros por cada cien escolarizados, se encuentran 5 de los 7 municipios de Lanzarote ${ }^{11}$ y 3 de los 6 de Fuerteventura ${ }^{12}$. Por

10. Y en un número sin determinar hijos de emigrantes retornados.

11. Y, de ésos, en todos los casos sobresalen los de UE y América Central y del Sur, salvo en la capital, Arrecife, donde priman sobre los de la UE, los de América Central y del Sur, África y Asia. En los otros dos municipios, Haría $(7,4 \%)$ y Tinajo $(5,0 \%)$, se sigue la misma tónica que en la mayoría de los municipios de la isla.

12. Lo que supone ponerse por encima de la media (9,2\%). En La Oliva y Antigua predominan los procedentes de América Central, del Sur y de la UE, en Pájara destacan los llegados de América Central y del Sur y casi a la par los africanos y los de la UE. En el resto de municipios: Puerto del Rosario, Tuineje y Betancuria, la proporción de alumnado extranjero respecto al autóctono es de 7,5 y 3 , respectivamente. En el caso de la capital, que recoge al 
encima de la media de la isla de Gran Canaria (4,7\%), se sitúan 3 de los 19 municipios de la isla: Mogán, San Bartolomé de Tirajana y Santa Lucía, con variedad de procedencias, como puede verse en la tabla $2^{13}$.

De los 31 municipios de Tenerife, 11 están por encima de la media de la isla (5,8\%): Arona, Adeje, San Miguel, Santiago del Teide, Granadilla, Guía de Isora, El Rosario, Vilaflor, Arico, Puerto de la Cruz y Candelaria ${ }^{14}$. En las islas menores occidentales, los procedentes de la UE y Latinoamérica son mayoría ${ }^{15}$.

$35,5 \%$ del alumnado extranjero de la isla (446 inmigrantes), el 60\% del alumnado es de América Central y del Sur, le siguen los procedentes de la UE (17,7\%) y de África (15,7\%).

13. Casi la mitad del alumnado extranjero en Mogán es de la Europa extracomunitaria, tienen también un peso importante los de UE y de América Central y del Sur. En San Bartolomé de Tirajana predominan, sin embargo, los llegados de la UE (43\%), seguido de América Central y del Sur, África y Asia. Mientras en Santa Lucía el 60\% son de América Central y del Sur y el 30\% de África. En el resto de la isla, cabe destacar la capital, Las Palmas de Gran Canaria, que escolariza al 44,8\% de los inmigrantes de la isla, siendo la mitad de América Central y del Sur (2.498), el 21\% de Asia, el 12,5\% de África y el 11\% de la UE.

14. Si echamos una ojeada a los de mayor concentración de inmigrantes en relación con la población escolar de la isla, vemos que:

En Arona, se reparten a partes iguales los llegados de América Central y del Sur y de la UE (38\% en cada caso), seguido de los asiáticos (12\%). Casi la mitad de los asiáticos y el $40 \%$ de los africanos de la isla están escolarizados en Arona. El 91\% de los extranjeros escolarizados en Adeje son de la UE y de América Central y del Sur. En San Miguel, el 73\% es de la UE, le siguen los asiáticos y los de América Central y del Sur. En Santiago del Teide, los de la UE casi doblan a los de América Central y del Sur, el tercer lugar lo ocupan los asiáticos. En Granadilla y Guía de Isora, los de América Central y del Sur doban a los de la UE. En Granadilla, le siguen los africanos, y en Guía, se reparten por igual africanos y asiáticos. En Arona, además, está escolarizado el 28\% del alumnado extranjero de la isla. A mucha distancia de la capital, Santa Cruz de Tenerife, que reúne al 14\%, y de La Laguna, al 8\%, en el caso de Adeje es el $9 \%$.

Curiosamente, el perfil del alumnado extranjero en La Laguna se halla escorado hacia los americanos del centro y del sur (77\%), seguido de africanos $(9,4 \%)$ y de la UE $(8,4 \%)$. La Laguna es el segundo municipio de la isla que destaca por tener una mayor concentración de africanos (17\%), después de Arona (38\%). Y es el tercer municipio con mayor número de americanos del centro y del sur de la isla (13\%), después de Arona (22\%) y de Santa Cruz de Tenerife (21\%). En Santa Cruz de Tenerife, el perfil del alumnado extranjero está formado mayormente por americanos del centro y del sur (75\%), seguido de europeos de la UE $(9 \%)$ y asiáticos $(8 \%)$. Es la capital el segundo municipio que más alberga a asiáticos de toda la isla (16,2\%), después de Arona (48,3\%).

15. En La Gomera, los dos municipios de los cinco que hay por encima de la media son Valle Gran Rey, donde el 69\% es de la UE, y Alajeró, que se reparte más entre procedentes de la UE y de América Central y del Sur, aunque predominan los primeros. En la capital, San Sebastián de La Gomera, destacan los de América Central y del Sur (48\%). En La Palma, por encima de la media están ocho municipios: Puntagorda, Garafía, Barlovento, El Paso, Fuencaliente, Breña Alta, Llanos de Aridane y Villa de Mazo. En Puntagorda, el 88\% de su alumnado extranjero es de la UE y el 100\% en el caso de Garafía. En Los Llanos y en Santa Cruz de La Palma, son mayoría los llegados de América Central y del Sur $(53$ y 62\%, respectivamente). Es en Los Llanos donde figura escolarizado el $40 \%$ del alumnado extranjero de la isla, seguido de Santa Cruz de La Palma (19\%). Y, en el Hierro, más del 80\% del alumnado extranjero es latinoamericano. 
Tabla 2. Municipios con mayor presencia de alumnado extranjero en relación con el autóctono y zona de procedencia. Canarias.

Curso 2002-2003

\begin{tabular}{|c|c|c|c|c|c|c|c|c|c|}
\hline & $\begin{array}{l}\% \text { alumnado extranjero } \\
\text { frente a autóctono }\end{array}$ & África & $\begin{array}{l}\text { América } \\
\text { Norte }\end{array}$ & $\begin{array}{l}\text { América } \\
\text { Central y del Sur }\end{array}$ & Asia & UE & $\begin{array}{l}\text { Resto } \\
\text { de Europa }\end{array}$ & Extranjeros & Españoles \\
\hline \multicolumn{10}{|l|}{ Lanzarote } \\
\hline Tías & 26,9 & 58 & 6 & 201 & 78 & 278 & 24 & 645 & 1.754 \\
\hline Yaiza & 15,8 & 32 & 0 & 59 & 19 & 55 & 1 & 166 & 885 \\
\hline Teguise & 11,9 & 7 & 3 & 57 & 22 & 166 & 15 & 270 & 2.001 \\
\hline Arrecife & 11,2 & 135 & 1 & 875 & 76 & 47 & 15 & 1.149 & 9.140 \\
\hline San Bartolomé & 11,2 & 31 & 1 & 156 & 10 & 69 & 7 & 274 & 2.162 \\
\hline \multicolumn{10}{|l|}{ Fuerteventura } \\
\hline La Oliva & 15,7 & 56 & 2 & 128 & 17 & 122 & 5 & 331 & 1.778 \\
\hline Pájara & 12,6 & 69 & 2 & 90 & 9 & 60 & 2 & 232 & 1.602 \\
\hline Antigua & 11,5 & 17 & 1 & 29 & 6 & 27 & 1 & 81 & 625 \\
\hline \multicolumn{10}{|l|}{ Gran Canaria } \\
\hline Mogán & 25,3 & 67 & 2 & 107 & 18 & 155 & 323 & 672 & 1.986 \\
\hline San Bartolomé de Tirajana & 12,4 & 149 & 3 & 179 & 130 & 407 & 75 & 943 & 6.665 \\
\hline Santa Lucía & 6,6 & 191 & 1 & 403 & 3 & 57 & 21 & 676 & 9.523 \\
\hline \multicolumn{10}{|l|}{ Tenerife } \\
\hline Arona & 20,8 & 120 & 4 & 733 & 235 & 733 & 91 & 1.916 & 7.293 \\
\hline Adeje & 18,4 & 14 & 1 & 249 & 28 & 331 & 17 & 640 & 2.840 \\
\hline San Miguel & 12,2 & 2 & 0 & 32 & 56 & 274 & 12 & 376 & 2.708 \\
\hline Santiago del Teide & 10,9 & 0 & 0 & 26 & 17 & 49 & 6 & 98 & 804 \\
\hline Granadilla de Abona & 9,2 & 42 & 0 & 269 & 6 & 126 & 18 & 461 & 4.565 \\
\hline Guía de Isora & 9,0 & 11 & 0 & 163 & 11 & 86 & 6 & 277 & 2.805 \\
\hline \multicolumn{10}{|l|}{ La Gomera } \\
\hline Valle Gran Rey & 14,5 & 0 & 0 & 13 & 5 & 40 & 0 & 58 & 341 \\
\hline Alajeró & 11,8 & 0 & 0 & 11 & 2 & 17 & 2 & 32 & 240 \\
\hline \multicolumn{10}{|l|}{ La Palma } \\
\hline Puntagorda & 14,0 & 0 & 0 & 5 & 0 & 43 & 1 & 49 & 301 \\
\hline Garafía & 11,5 & 0 & 0 & 0 & 0 & 11 & 0 & 11 & 85 \\
\hline Barlovento & 10,7 & 0 & 0 & 3 & 0 & 0 & 0 & 3 & 25 \\
\hline \multicolumn{10}{|l|}{ El Hierro } \\
\hline Valverde & 7,0 & 0 & 0 & 44 & 0 & 11 & 0 & 55 & 728 \\
\hline Frontera & 5,4 & 0 & 0 & 13 & 0 & 2 & 0 & 15 & 263 \\
\hline
\end{tabular}

Fuente: elaboración propia con datos del ICEC (2005). 


\section{Alumnado extranjero en educación postobligatoria. Una elección marcada por la zona de procedencia}

Analicemos cómo se distribuye el alumnado en los distintos niveles educativos según procedencia. La información sobre el peso de las distintas nacionalidades en la educación obligatoria por sí sola no nos sirve de mucho, aunque ésta sea la facilitada por las estadísticas. El carácter de obligatoriedad y la variación clara en el alumnado por la representatividad del lugar de llegada no nos aporta gran $\operatorname{cosa}^{16}$. Más interesante es ver cómo se distribuyen en la educación secundaria postobligatoria, distinguiendo entre formación profesional (FP) y bachillerato. Otro dato de valor sería contrastar cuántos alumnos y alumnas de los que cursaron educación obligatoria pasaron a una educación secundaria postobligatoria, pero esto precisaría contar con los datos de al menos dos cursos consecutivos, y sólo se dispone de la distribución por niveles educativos en el curso 2004-2005 ${ }^{17}$. En cualquier caso, utilizaremos, a modo de aproximación, los datos del mismo curso, siendo conscientes de las limitaciones que ello supone.

Por tanto, en el archipiélago canario, como refleja la tabla 3, la nacionalidad del alumnado con mayor presencia en secundaria postobligatoria respecto a la educación obligatoria puede ordenarse según continentes como sigue: Europa, Asia, África y América. Pero si perfilamos algo más distinguiendo

16. Distintas explicaciones se han dado a la distribución del alumnado extranjero según niveles educativos. Probablemente éste sea uno de los elementos más secundarios de la información facilitada por las estadísticas, fundamentalmente porque son múltiples las explicaciones coyunturales que hacen difícil un seguimiento de la información con cierta lógica. Así, por ejemplo, uno de los aspectos que reflejan los datos es que, a lo largo de la década de 1990, han aumentado los extranjeros matriculados en secundaria, particularmente en ESO, lo que puede tener el efecto claro de la LOGSE en ampliación de la educación obligatoria que ofrece esas diferencias según procedencias. Pero para realizar un análisis más certero de la situación, habría que hacer un seguimiento del alumnado inmigrante y así descartar una explicación tan simple como que un aumento de esta matrícula tuviera que ver con su edad de llegada.

Más sentido tiene la educación postobligatoria, donde sí se observan diferencias importantes, de nuevo asociadas a procedencias favorecidas en el caso de los estudios de bachillerato (puede verse Defensor del Pueblo, 2003:16). Canarias, en el curso 2000-2001, es la primera comunidad autónoma con mayor proporción de alumnado en educación postobligatoria, duplica casi la media española (17 alumnos por cada mil en el archipiélago frente a 9 en España). Esto podría entenderse como un indicador del tipo de alumnado extranjero que vive en las islas, si bien es un dato que requeriría mayor análisis, dado que se agrupa bajo la educación secundaria postobligatoria un conjunto muy variopinto de ramas (bachillerato, FPII, ciclos formativos de FP y programas de garantía social) (INCE, 2002).

17. La información de este curso académico fue facilitada por el ICEC en datos brutos por cada una de las nacionalidades presentes en Canarias y por todos los niveles educativos registrados: infantil, primaria, educación especial, ESO, bachillerato, ciclo formativo de grado medio y ciclo formativo de grado superior, distinguiendo en la educación postobligatoria entre ordinario, nocturno/adulto y a distancia, PGS, enseñanza en la escuela oficial de idiomas y enseñanza de adultos. Aunque solicitamos información sobre otros cursos anteriores, sólo se disponía de éste. Agradecemos la colaboración de dicha institución. 
Tabla 3. Distribución del alumnado por nivel educativo y zona de procedencia. Canarias. Curso 2004-2005

\begin{tabular}{lccccc}
\hline & $\begin{array}{l}\text { No Alumnos } \\
\text { en educación } \\
\text { obligatoria } \\
\text { (primaria y ESO) }\end{array}$ & $\begin{array}{l}\text { \% Alumnado } \\
\text { en educación } \\
\text { secundaria postobligatoria } \\
\text { respecto a la obligatoria }\end{array}$ & $\begin{array}{l}\text { \% Alumnado } \\
\text { en bachiller }\end{array}$ & $\begin{array}{l}\text { \% Alumnado } \\
\text { en FPGM }\end{array}$ & $\begin{array}{l}\text { \% Alumnado } \\
\text { en FPGS } \\
\text { respecto a } \\
\text { bachiller }\end{array}$ \\
\hline Europa & 5.162 & 13,4 & 88,6 & 11,4 & 17,6 \\
UE & 4.515 & 11,9 & 86,2 & 13,8 & 21,2 \\
Resto de Europa & 647 & 23,9 & 96,7 & 3,2 & 6,6 \\
\hline África & 1.442 & 11,9 & 59,9 & 40,1 & 43,7 \\
Norte de África & 1.164 & 8,3 & 68,1 & 31,9 & 21,2 \\
Resto de África & 293 & 25,6 & 49,3 & 50,7 & 83,8 \\
\hline Asia & 1.267 & 12,4 & 91,1 & 8,9 & 6,9 \\
\hline América & 9.254 & 10,9 & 76,8 & 23,2 & 36,6 \\
América del Norte & 106 & 21,7 & 87,0 & 13,0 & 5,0 \\
América Central & 967 & 16,7 & 76,0 & 24,0 & 26,8 \\
América del Sur & 8.181 & 10,1 & 76,7 & 23,3 & 39,5 \\
\hline Canarias* & 209.218 & 21,3 & 71,5 & 28,5 & 34,3 \\
\hline
\end{tabular}

Fuente: elaboración propia con datos ICEC (2006), sin publicar. Elaboración propia con datos avance del MEC.

según sean europeos de la UE o del Resto de Europa y de América del Norte, Central o del Sur, el orden varía: Resto de Europa (23,9\%), América del Norte $(21,7 \%)$, América Central (16,7\%), Asia (12,4\%), África y UE con un porcentaje similar $(11,9 \%)$ y, finalmente, América del Sur (10,1\%).

Pocas veces encontramos dividido el continente africano. Si distinguimos entre África del Norte y resto de África, la distribución anterior varía de un modo que podría sorprendernos a priori. El primer lugar con mayor proporción de alumnado en secundaria postobligatoria respecto a la obligatoriedad lo ocuparía el resto de África (25,6\%), antes que el resto de Europa, mientras que el último puesto estaría representado por los llegados del norte de África $(8,3 \%)$.

¿Cómo explicar el porqué de esa situación? El grupo minoritario y, por tanto, con mayor probabilidad de error, es el procedente del resto de Africa, pero eso no hace desestimar su distribución. A priori, podríamos pensar que el alumnado procedente de África, sin ser de la zona norte, llega con una edad superior al que proviene de los otros lugares y ello ayudaría a explicar su mayor número en educación secundaria postobligatoria. De ser éste un argumento satisfactorio, las circunstancias desfavorecidas en principio atribuibles a este colectivo reflejarían una mayor presencia en las ramas menos nobles. Y así es. Si contrastamos la división entre bachillerato y formación profesional de grado medio (FPGM) según nacionalidades, puede verse que son los llegados de África los que tienen menor proporción de su alumnado en bachillerato y más en FPGM. Y si tomamos como referencia la división en grandes partes de los continentes, es el alumnado llegado del resto de África el único colectivo donde 
prácticamente se equiparan los estudiantes en las dos ramas, mientras que en las otras zonas de procedencia resaltan los matriculados en bachillerato sobre los que lo hacen en FPGM, de manera que los continentes se ordenan de menor a mayor presencia en bachillerato como sigue: África (60\%), América $(76,8 \%)$, Europa $(88,6 \%)$ y Asia $(91,1 \%)$. Y por grandes agrupamientos dentro de esos continentes: resto de África (49,3\%), norte de África (68\%), América Central (76\%), América del Sur (76,7\%), Unión Europea (86,2\%), América del Norte $(87 \%)$, Asia $(91,1 \%)$ y resto de Europa (96,7\%).

Es interesante destacar la posición del alumnado canario entre las distintas nacionalidades en esta división entre FPGM y bachiller, dado que se ubica tras los africanos como el colectivo con mayor presencia en formación profesional. Un indicador sin duda de gran relevancia para entender la situación del alumnado inmigrante en el archipiélago.

Hasta aquí una información clave sobre la distribución del alumnado, dado que se constata cómo el alumnado llegado de las zonas de procedencia más ricas acude a la rama noble del sistema educativo, mientras que el llegado de las zonas más pobres acude a la rama educativa más pobre, peor valorada y que capacita para puestos de trabajo más subalternos, peor pagados y de menor prestigio.

Si añadimos a lo dicho cómo se distribuyen las distintas nacionalidades en el reducto, cajón de sastre del sistema educativo, como son los programas de garantía social (PGS), aún más se constata lo dicho. En comparación con el alumnado matriculado en la educación obligatoria de cada nacionalidad, esta enseñanza estaría integrada por el $0,1 \%$ de los asiáticos, el $0,3 \%$ de los europeos, el 0,6\% de los americanos y el 2,3\% de los africanos.

En cambio, ¿qué pasará en la matrícula en la formación profesional de grado superior (FPGS) ${ }^{18}$. De nuevo el alumnado de zonas de procedencia más ricas es más que probable que, al finalizar bachillerato, acuda a la universidad y no a FPGS, al contrario de lo que ocurriría con el alumnado de zonas más pobres. Lo que, como puede verse en la tabla 3 , ayudaría a entender que fuera en el alumnado procedente de África (y particularmente del resto de África) y en segundo lugar en el de América (especialmente de América del Sur) donde se halla la mayor proporción de alumnado en FPGS respecto a sus compatriotas matriculados en bachiller. Y en el lado opuesto, destacarían los llegados de América del Norte, del resto de Europa y de Asia.

18. Como decíamos, no es el objetivo de este artículo realizar el análisis de la educación universitaria, pero echemos una ojeada a la educación superior no universitaria. En este caso, la comparación más lógica podría hacerse respecto al alumnado matriculado en educación secundaria postobligatoria. Podríamos tener dudas sobre si establecer la comparación sólo con la vía normal de acceso, bachillerato, o con la FPGM, que, aún sin ser la vía normal, la normativa en vigor, y las anteriores desde la LOGSE, permiten una posibilidad de acceso. Hemos seguido el criterio genérico, pero aún así nos enfrentamos a otras limitaciones, dado que, por un lado, el alumnado que acude a bachillerato normalmente lo hace con el objetivo de ir a la universidad y no de acudir a FPGS y, por otro, desconocemos el porcentaje de abandonos de bachiller y el de matriculados en la universidad. 
Tabla 4. Distribución del alumnado por nivel educativo según nacionalidad con mayor presencia por continente. Canarias. Curso 2004-2005

\begin{tabular}{lccccc}
\hline & $\begin{array}{l}\text { \% de alumnado } \\
\text { en secundaria } \\
\text { postobligatoria } \\
\text { respecto a la } \\
\text { obligatoria }\end{array}$ & $\begin{array}{l}\text { \% de alumnado } \\
\text { en educación } \\
\text { obligatoria }\end{array}$ & $\begin{array}{l}\text { \% de alumnado } \\
\text { en FPGM }\end{array}$ & $\begin{array}{l}\text { \% de alumnador } \\
\text { en FPGS } \\
\text { respecto a } \\
\text { bachiller }\end{array}$ \\
\hline $\begin{array}{l}\text { De UE: } \\
\text { Reino Unido }\end{array}$ & 1.663 & 4,5 & 93,3 & 6,7 & 12,8 \\
$\begin{array}{l}\text { Del resto de Europa: } \\
\text { Noruega }\end{array}$ & 210 & 41,4 & 98,8 & 1,2 & 1,1 \\
$\begin{array}{l}\text { De África: } \\
\text { Marruecos }\end{array}$ & 936 & 7,9 & 66,2 & 33,8 & 20,4 \\
$\begin{array}{l}\text { De Asia: } \\
\text { China }\end{array}$ & 595 & 7,7 & 93,5 & 6,5 & 4,6 \\
$\begin{array}{l}\text { De América del Norte: } \\
\text { EEUU }\end{array}$ & 69 & 27,5 & 94,7 & 5,3 & 28,9 \\
$\begin{array}{l}\text { De América Central: } \\
\text { Cuba }\end{array}$ & 711 & 17,0 & 80,2 & 19,8 & 43,9 \\
$\begin{array}{l}\text { De América del Sur: } \\
\text { Colombia }\end{array}$ & 2.613 & 9,7 & 70,9 & 29,1 & \\
\hline
\end{tabular}

Fuente: elaboración propia con datos del ICEC (2006).

Como ha demostrado la bibliografía científica, la mayoría del alumnado que estudia FPGM lo hace con un objetivo terminal y es un alumnado con un perfil más subalterno. Por tanto, no es de extrañar lo que nos demuestran los datos. Hay más alumnos en FPGS que en FPGM entre el procedente de Europa (108 y 79 respectivamente) y de América (284 y 234), salvo en América del Norte. En cambio, aunque probablemente por razones muy distintas, hay más alumnado cursando FPGM que FPGS entre el africano (69 y 45 respectivamente) y entre el asiático (14 y 10 $)^{19}$.

Todo lo dicho hasta el momento podría analizarse por nacionalidades, pero no es el objetivo de este trabajo, no sólo por lo tedioso que podría representar para el lector, sino también por cuestión de espacio. Sólo una cuestión, una constatación más a lo que venimos diciendo. Como puede verse en la tabla 4, donde se recoge la distribución señalada entre el alumnado de la nacionalidad de mayor matrícula en el archipiélago por cada una de las zonas de procedencia, es imposible referirnos a los inmigrantes como un colectivo homogéneo, incluso dentro del espacio de una comunidad autónoma y, por tanto, insostenible todo análisis e inviable toda política educativa que no atienda a estas

19. En este último caso, el escaso número de alumnos puede alterar los datos. Téngase en cuenta que estamos hablando de sólo 24 alumnos entre ambos niveles de formación profesional, es decir, equivale al 1,9\% del alumnado asiático en educación obligatoria. Mientras que el alumnado africano en FP suma 114 alumnos, el 7,9\% del alumnado africano en educación obligatoria. La media de todo el alumnado extranjero en Canarias es del 4,9\% (3,6\% en el caso de Europa y el 5,6\% en el de América). 
enormes diferencias. Y es que un alumnado británico, noruego, marroquí, chino, estadounidense, cubano o colombiano tiene más diferencias que semejanzas en su trayectoria educativa.

\section{Distribución del alumnado extranjero según la titularidad de los centros. La privatización de la diferencia}

El amparo en la libertad de elección de centro de los padres es uno de los elementos esgrimido para seguir justificando la doble titularidad, aunque entra en contradicción con otro de los principios fundamentales, la igualdad de oportunidades. Si la distribución del alumnado según la titularidad de los centros sigue obedeciendo a criterios socioeconómicos y socioculturales, parece lógico pensar que afecte de igual forma al alumnado extranjero, de manera que los llegados de zonas más desfavorecidas acuden a centros públicos y los de zonas más favorecidas, a centros privados ${ }^{20}$ (Defensor del Pueblo, 2003: 12-13). En cambio, no es esta situación la que se denuncia, sino la relegación del alumnado inmigrante a los centros públicos.

Las denuncias por saltarse la ley vienen de la población inmigrante, lo cual demostraría varias cosas: en primer lugar, contar con asociaciones de apoyo de gran peso, que el tema de la inmigración se haya colocado en un primer plano y que una de las desigualdades más reconocidas en los últimos tiempos sea la de la etnia ${ }^{21}$ por encima de las clases sociales; y, en segundo lugar, que entre los inmigrantes existen diversas procedencias, algunos tienen un posicionamiento social y cultural que choca con la imagen del inmigrante más extendida, poseen suficientes conocimientos para denunciar situaciones de injusticia en primer plano. Algo que no puede ser generalizable a la población local.

Se hace necesario insistir en que se ha convertido en una tónica habitual olvidarse tanto de que los inmigrantes tienen clase social como de que hay otros colectivos sociales no inmigrantes que tienen una situación comparativamente más desfavorable socialmente y que se han quedado sin valedores, suplantados por el tema de $\operatorname{moda}^{22}$. En este contexto, llaman la atención valoraciones como las recogidas en el informe del Defensor del Pueblo,

20. Cuando decimos que es la zona de procedencia la que determina a grandes rasgos que el alumnado inmigrante acuda a un centro público o privado, nos referimos a situaciones socioculturales y económicas determinadas más allá de las excepciones, más que posibles, pero imposibles de detectar en un estudio de este tipo. Aludimos a inmigrantes del norte o del sur en sentido social y de manera más desagregada a la división agrupada por países de procedencia que siguen las estadísticas.

21. Podría afirmarse que siguen aplicándose mecanismos de disuasión para seleccionar al alumnado en el acceso a los centros concertados ya clásicos y aparecen otros nuevos, por ejemplo: el ideario religioso de algunos centros (Aja-Larios, 2003). Los autores citan las irregularidades cometidas por los centros concertados en el caso particular de Cataluña, que, según Auditoría de 2001, abarcaba al 50\% de estos centros.

22. Algunos estudios han subrayado que las actitudes hacia los inmigrantes en España son más positivas que hacia otros grupos sociales objeto de discriminación, marginación o exclusión social. Puede verse Díez y Ramírez (2001: 310). 
donde se dice que la adopción de las medidas que se recomiendan debe hacerse en un contexto donde la población autóctona de similares niveles socioeconómicos mantenga, al menos, las mismas expectativas de acceso a ayudas económicas o de cualquier otra índole que hasta el momento obtenían del sistema educativo (Defensor del Pueblo, 2003: VIII-XIX). En esta misma lógica, habría que añadir que el debate sobre la admisión del alumnado en los centros y la distribución entre éstos debería generalizarse a todo el alumnado.

Las regulaciones de las leyes educativas en los apartados dedicados a los inmigrantes parecen considerar inmigrantes sólo a los económicos, aunque bajo el nombre genérico de inmigrantes, pero se recomienda en ocasiones seguir una vía educativa con menor relevancia social. Pero, por otro lado, la financiación de la educación privada con fondos públicos que supone en la práctica privilegiar a un alumnado que ya lo es socialmente, abarca también al alumnado extranjero que comparte esta situación. Es decir, la realidad del sistema educativo nos muestra a un colectivo de inmigrantes que busca diferenciarse "por arriba» de otros inmigrantes y de la población autóctona.

Las comunidades autónomas difieren en la privatización de la educación y en la distribución del alumnado según titularidad de los centros (ICEC, 2002; MEC, 2005c). Comentemos algunos de estos aspectos.

Canarias es la tercera comunidad autónoma en acoger al alumnado procedente de la UE y de América del Norte de todo el matriculado en España, tanto en centros públicos como en privados ${ }^{23}$. Con los asiáticos, se coloca en la quinta comunidad autónoma de los inscritos en centros públicos y la tercera en los privados ${ }^{24}$. Las profesiones de los asiáticos que viven en el archipiélago (fundamentalmente, empresarios del sector comercial, que sobresalen de manera abrumadora en los directivos y gerentes, el 36\%) explicaría esta situación (Zamora, 2003: 195). Una tónica similar ocurre con los llegados del resto de Europa, dado el mayor nivel educativo de sus familias y el peso de la escolarización en centros privados docentes extranjeros puros de gran parte de algunas de las zonas del resto de Europa como Noruega o Suiza ${ }^{25}$. En las otras procedencias, la tónica es bien diferente ${ }^{26}$.

23. Del alumnado de la UE matriculado en centros públicos españoles, $12,2 \%$ lo hace en Canarias y de los matriculados en centros privados españoles, 10,1\% lo hacen en Canarias (MEC, 2005c: E4.2 referidos al curso 2002-2003).

24. En Canarias está el 8,9\% de los matriculados en centros públicos y el 13,2\% de los que lo hacen en centros privados. Es decir, en este último colectivo, el archipiélago destaca por concentrar una proporción importante en centros privados, incluso superior a la que representa la presencia de asiáticos en centros públicos.

25. El alumnado en Canarias llegado de la Europa extracomunitaria procede de dos zonas que obedecen a características muy distintas: $a$ ) países desarrollados (Noruega, Suiza e Islandia), que forman el $48 \%$ del alumnado llegado de esa zona y $b$ ) países de Europa del Este y de la Europa menos avanzada (ICEC, 2005: 3). Es el primer grupo el que forma la matrícula en centros privados extranjeros, como puede verse en el nombre de los mismos. El 6,7\% de los que acuden a centros privados, lo hacen en Canarias (quinta posición), mientras que sólo el 1,8\% de los que se escolarizan en centros públicos (10 a posición). 
Son los procedentes de Europa los que tienen las mejores profesiones y el mayor nivel de estudios, con mayor proporción de estudios universitarios frente al resto de inmigrantes. Entre los analfabetos, destacan los africanos, y entre los sin estudio, los americanos, si bien en unos y otros predominan perfiles educativos similares, sobresaliendo los que poseen estudios secundarios, seguido de primarios y sin estudios. Una tónica bien distinta a los europeos y los asiáticos, donde predominan los estudios secundarios. El segundo nivel de estudios de los primeros es, en la misma proporción, universitario y primario, y los asiáticos siguen una tónica similar a los africanos y americanos, pero destacan con una proporción bastante mayor de estudios secundarios (Zamora, 2003: 195, 197).

La distribución entre centros públicos y privados ha sufrido algunas modificaciones en años recientes, como puede verse en la tabla 5. En comparación con la media española, el alumnado procedente de Europa y de Asia, a diferencia del resto de inmigrantes, se encuentra más escolarizado en centros privados en Canarias que en el resto del Estado. Aunque no siempre con el mismo peso, esta situación ha sido una constante en los seis cursos académicos analizados, lo cual es todavía más llamativo si tenemos en cuenta la mayor cantidad de centros privados en la Península. Como refleja la tabla 5, la diferencia porcentual en la privatización de los del resto de Europa ha pasado de ser superior a 20 puntos en los primeros cursos a algo más de 10 en el último, debido a la incorporación de los nuevos países a la UE, con un peso importante en las islas. En el alumnado de la UE, las distancias se agrandan en el último curso, no por una disminución sustancial en la privatización en Canarias, sino por el descenso de la misma en España. Y en el caso de Asia, el descenso en la privatización en Canarias en los años estudiados (de casi 30 puntos) ha hecho acortar diferencias con la media nacional.

En líneas generales, puede afirmarse que, en los últimos cursos académicos, ha variado la distribución del alumnado extranjero según titularidad de los centros, disminuyendo la privatización. Pero la variación por comunidades autónomas es importante, como recoge la tabla 6 . La situación descrita ha sido más notoria en Canarias, Andalucía y Navarra (con un descenso en torno a diez o más puntos porcentuales entre 2000-2001 y 2004-2005). La misma tónica, pero con menor diferencia, se ha producido en Cantabria y en la Comunidad Valenciana. Sin embargo, en La Rioja, Castilla y León y Melilla la lógica es la contraria, en el primer caso, se mantiene y en las otras comunidades disminuye el alumnado extranjero matriculado en centros públicos y aumenta el que lo hace en los centros privados. Una posible explicación a estas varia-

26. Por poner algunos ejemplos: los africanos que llegan a Canarias casi no tienen representación en los centros privados (sólo el 0,5\% de los procedentes del norte de África que se escolarizan en centros privados lo hacen en Canarias, esta comunidad autónoma se coloca en la $17^{\mathrm{a}}$ posición, que comparte con Melilla), de manera similar ocurre con los americanos del centro y del sur. En estos últimos, de los escolarizados en centros privados, el 1,3\% lo hace en Canarias (posición14a), mientras que la distribución en centros públicos es de $6,4 \%$ (posición 5a). 
Tabla 5. Distribución porcentual del alumnado extranjero en centros privados, según zona de procedencia

\begin{tabular}{clllllllll}
\hline Cursos & & Resto de Europa & Unión Europea & África & América del Norte & América Central & América del Sur & Asia & Oceanía \\
\hline 1999-2000 España & 28,51 & 36,09 & 10,42 & 45,60 & 19,23 & 22,61 & 34,09 & 26,57 \\
& Canarias & 55,53 & 39,80 & 4,06 & 30,77 & 5,11 & 7,20 & 59,85 & 6,67 \\
\hline 2000-2001 España & 21,87 & 33,86 & 10,58 & 45,15 & 18,90 & 21,44 & 32,57 & 25,37 \\
Canarias & 40,46 & 35,85 & 2,83 & 35,71 & 4,60 & 5,47 & 52,70 & 28,57 \\
\hline 2001-2002 España & 19,63 & 32,92 & 10,94 & 46,34 & 19,94 & 19,64 & 31,30 & 32,54 \\
Canarias & 39,66 & 33,79 & 1,73 & 35,38 & 4,91 & 3,48 & 41,92 & 10,00 \\
\hline 2002-2003 España & 16,56 & 35,97 & 11,59 & 43,68 & 21,30 & 18,99 & 32,10 & 29,25 \\
Canarias & 42,80 & 31,83 & 2,11 & 36,99 & 5,34 & 4,64 & 41,32 & 18,18 \\
\hline 2003-2004 España & 15,04 & 30,15 & 11,35 & 43,91 & 21,39 & 18,65 & 29,40 & 33,33 \\
Canarias & 33,80 & 31,24 & 1,59 & 27,42 & 6,52 & 4,12 & 32,28 & 25,00 \\
\hline 2004-2005 España & 14,96 & 25,21 & 10,99 & 42,31 & 21,71 & 18,57 & 29,34 & 27,43 \\
Canarias & 25,44 & 35,72 & 1,98 & 21,84 & 6,88 & 4,75 & 30,78 & 00,00 \\
\hline
\end{tabular}

Fuente: elaboración propia con datos del MEC. 
Tabla 6. Porcentaje de alumnado extranjero según titularidad del centro

\begin{tabular}{|c|c|c|c|c|c|c|c|c|c|c|}
\hline & \multicolumn{2}{|c|}{$2000-2001$} & \multicolumn{2}{|c|}{$2001-2002$} & \multicolumn{2}{|c|}{$2002-2003$} & \multicolumn{2}{|c|}{$2003-2004$} & \multicolumn{2}{|c|}{ 2004-2005 } \\
\hline & Púb. & Priv. & Púb. & Priv. & Púb. & Priv. & Púb. & Priv. & Púb. & Priv. \\
\hline Total & 77,7 & 22,3 & 79,0 & 21,0 & 79,3 & 20,7 & 80,8 & 19,2 & 81,6 & 18,4 \\
\hline Andalucía & 72,5 & 27,5 & 75,5 & 24,5 & 73,8 & 26,2 & 81,9 & 18,1 & 83,0 & 17,0 \\
\hline Aragón & 76,9 & 23,1 & 77,8 & 22,2 & 75,7 & 24,3 & 77,2 & 22,8 & 77,6 & 22,4 \\
\hline Asturias & 85,7 & 14,3 & 83,1 & 16,9 & 81,0 & 19,0 & 82,3 & 17,7 & 81,5 & 18,5 \\
\hline Balears (Illes) & 81,2 & 18,8 & 82,0 & 18,0 & 82,0 & 18,0 & 80,8 & 19,2 & 81,8 & 18,2 \\
\hline Canarias & 74,6 & 25,4 & 80,9 & 19,1 & 82,5 & 17,5 & 85,0 & 15,0 & 86,4 & 13,6 \\
\hline Cantabria & 65,6 & 34,4 & 68,6 & 31,4 & 68,5 & 31,5 & 68,4 & 31,6 & 72,6 & 27,4 \\
\hline Castilla y León & 81,8 & 18,2 & 78,1 & 21,9 & 78,9 & 21,1 & 76,8 & 23,2 & 75,7 & 24,3 \\
\hline Castilla La Mancha & 88,5 & 11,5 & 89,9 & 10,1 & 88,7 & 11,3 & 88,6 & 11,4 & 89,6 & 10,4 \\
\hline Cataluña & 83,2 & 16,8 & 82,9 & 17,1 & 82,0 & 18,0 & 83,4 & 16,6 & 84,1 & 15,9 \\
\hline Comunidad Valenciana & 81,9 & 18,1 & 83,7 & 16,3 & 84,5 & 15,5 & 85,3 & 14,7 & 86,0 & 14,0 \\
\hline Extremadura & 92,1 & 7,9 & 94,9 & 5,1 & 91,3 & 8,7 & 90,4 & 9,6 & 91,4 & 8,6 \\
\hline Galicia & 85,2 & 14,8 & 84,7 & 15,3 & 83,8 & 16,2 & 84,3 & 15,7 & 84,4 & 15,6 \\
\hline Madrid & 72,2 & 27,8 & 72,8 & 27,2 & 73,9 & 26,1 & 74,0 & 26,0 & 74,6 & 25,4 \\
\hline Murcia & 89,6 & 10,4 & 89,5 & 10,5 & 90,0 & 10,0 & 88,9 & 11,1 & 89,1 & 10,9 \\
\hline Navarra & 70,8 & 29,2 & 76,3 & 23,7 & 78,6 & 21,4 & 79,8 & 20,2 & 80,7 & 19,3 \\
\hline País Vasco & 70,0 & 30,0 & 69,4 & 30,6 & 71,5 & 28,5 & 70,5 & 29,5 & 66,5 & 33,5 \\
\hline La Rioja & 86,9 & 13,1 & 78,8 & 21,2 & 77,0 & 23,0 & 77,2 & 22,8 & 77,1 & 22,9 \\
\hline Ceuta & 89,1 & 10,9 & 94,1 & 5,9 & 69,1 & 30,9 & 85,2 & 14,8 & 88,0 & 12,0 \\
\hline Melilla & 99,0 & 1,0 & 97,1 & 2,9 & 93,4 & 6,6 & 93,3 & 6,7 & 92,4 & 7,6 \\
\hline
\end{tabular}

Fuente: elaboración propia a partir de datos del MEC (2005a).

ciones sería el cambio de tendencia inmigratoria por comunidades autónomas, pero habría que comprobarlo.

En cualquier caso, la distribución del alumnado extranjero en los centros privados en el ámbito estatal es menos de la mitad de la que acude a los centros públicos. Ésta es una constatación que afecta prácticamente a todos los niveles educativos, también a la enseñanza secundaria postobligatoria, salvo a FP (MEC, 2005b). Es decir, el 6,5\% de inmigrantes que hay en España en el curso 2004-2005 es del 7,8\% en centros públicos y del 3,7\% en centros privados.

\section{Alumnado inmigrante y autóctono en centros privados. El peso de la reproducción social}

La comparación entre Canarias y Estado español muestra una mayor presencia en los centros privados en el archipiélago de alumnado extranjero, como puede verse en la tabla 7 , respecto al alumnado autóctono. 
Tabla 7. Alumnado extranjero matriculado por cada 1.000 alumnos

\begin{tabular}{|c|c|c|c|c|c|c|c|c|c|c|}
\hline \multirow[b]{2}{*}{ Cursos } & & \multicolumn{3}{|c|}{ Educación infantil } & \multicolumn{3}{|c|}{ Educación primaria } & \multicolumn{3}{|l|}{ ESO } \\
\hline & & Total & Públ. & Priv. & Total & Públ. & Priv. & Total & Públ. & Priv. \\
\hline \multirow[t]{2}{*}{$2002-2003$} & Cana & 48,7 & 52,4 & 35,5 & 58,4 & 64,8 & 39,1 & 57,4 & 60,8 & 46,0 \\
\hline & España & 47,3 & 57,3 & 28,3 & 53,7 & 65,2 & 31,0 & 43,0 & 51,5 & 26,5 \\
\hline \multirow[t]{2}{*}{$2003-2004$} & Canarias & 58,8 & 63,0 & 44,0 & 73,3 & 81,1 & 50,1 & 66,1 & 73,4 & 42,1 \\
\hline & España & 58,0 & 71,9 & 32,1 & 69,7 & 85,1 & 38,8 & 57,8 & 69,4 & 35,2 \\
\hline
\end{tabular}

Fuente: CES (2004) (2005: 181) ${ }^{27}$.

A pesar del incremento al que hacíamos referencia en el sector público que afecta a todos los niveles educativos, en educación infantil el crecimiento en la matrícula ha seguido una misma tónica en los centros públicos y privados; en cambio, en educación primaria, el crecimiento de la escolarización en los centros privados ha sido mayor en Canarias. De nuevo, la explicación parece estar en las características de los inmigrantes, que aquí hemos reducido a las zonas de procedencia. Un estudio más completo sobre posición social sería sin duda un indicador de mayor relevancia.

Contrastando el acceso a la educación privada entre alumnado inmigrante y autóctono en España, vemos cómo los llegados de América del Norte acuden mucho más a centros privados que la población autóctona, los de América del Sur y Asia siguen una tónica similar a los autóctonos, los de América Central y Europa no comunitaria lo hacen en menor proporción y los alumnos procedentes de África son prácticamente inexistentes en los centros privados (Fernández Enguita, 2003: 249).

En Canarias, sin embargo, la presencia en centros privados es diferente. Predominan los llegados de Europa no comunitaria, de Asia y de América del Norte (4 de cada 10 de cada uno de estos colectivos), seguidos de la Europa comunitaria (3 de cada 10) y a mucha distancia de América Central, del Sur y África ${ }^{28}$.

Lo llamativo es que Canarias es la segunda comunidad autónoma con mayor proporción de alumnado extranjero en "centros privados extranjeros» con un 10,5\% de alumnos/as (la media española es de 7,5\%), después de Andalucía $(17,7 \%)$ y a mucha distancia de Madrid $(3,1 \%)$ y del País Vasco $(2,4 \%)$ y la Comunidad Valenciana $(0,3 \%)$, únicas comunidades autónomas con centros de este tipo en el curso 2002-2003. De tal forma que, en Canarias, la mayoría de los extranjeros que se matricula en centros privados lo hace en cen-

27. Los datos que ofrece el CES de Canarias y el MEC (2005c), referidos a datos del curso 2002-2003, tienen algunas diferencias entre sí, aunque mínimas.

28. Hay ciertas diferencias en los porcentajes según utilicemos la fuente del MEC que hemos empleado aquí, o la del ICEC (2005: 29-30). La más notoria se da con los americanos del norte, dado que, según el ICEC, estarían matriculados en educación privada 5 de cada 10. 
Tabla 8. Porcentaje de alumnado extranjero en centros privados extranjeros y privados no extranjeros. Curso 2002-2003

\begin{tabular}{|c|c|c|c|c|c|c|c|c|c|c|c|}
\hline & \multirow[b]{2}{*}{ Centros privados } & \multirow[b]{2}{*}{ Total } & \multicolumn{2}{|c|}{ Europa } & \multicolumn{2}{|l|}{ África } & \multicolumn{3}{|c|}{ América } & \multirow[b]{2}{*}{ Asia } & \multirow[b]{2}{*}{ Oceanía } \\
\hline & & & $\mathrm{UE}$ & Resto & Norte & Resto & Norte & Centro & Sur & & \\
\hline \multirow[t]{2}{*}{ Canarias } & No extranjeros & 7,0 & 12,6 & 7,8 & 0,8 & 1,8 & 4,8 & 3,8 & 4,2 & 10,6 & 18,2 \\
\hline & Extranjeros & 10,5 & 19,2 & 35,0 & 1,2 & 0,8 & 32,2 & 1,6 & 0,4 & 30,7 & 0,0 \\
\hline \multirow[t]{2}{*}{ España } & No extranjeros & 17,2 & 16,0 & 14,4 & 10,0 & 18,2 & 40,0 & 21,2 & 18,9 & 27,4 & 25,5 \\
\hline & Extranjeros & 3,5 & 19,9 & 2,2 & 0,3 & 0,4 & 3,7 & 0,2 & 0,1 & 4,7 & 3,7 \\
\hline
\end{tabular}

Fuente: elaboración propia con datos del MEC (2005c).

Tabla 9. Porcentaje de alumnado (total y extranjero) según la titularidad de los centros

\begin{tabular}{|c|c|c|c|c|c|}
\hline \multirow{2}{*}{ Cursos } & & \multicolumn{2}{|c|}{ Alumnado total } & \multicolumn{2}{|c|}{ Alumnado extranjero } \\
\hline & & C. públicos & C. privados & C. públicos & C. privados \\
\hline \multirow[t]{2}{*}{$1999-2000$} & España & 68,28 & 31,71 & 76,06 & 24,21 \\
\hline & Canarias & 79,85 & 20,14 & 68,55 & 31,44 \\
\hline \multirow[t]{2}{*}{$2000-2001$} & España & 67,79 & 32,20 & 77,65 & 22,34 \\
\hline & Canarias & 79,36 & 20,64 & 74,55 & 25,45 \\
\hline \multirow[t]{2}{*}{$2001-2002$} & España & 67,43 & 32,57 & 79,04 & 20,96 \\
\hline & Canarias & 78,88 & 21,12 & 80,92 & 19,08 \\
\hline \multirow[t]{2}{*}{$2002-2003$} & España & 67,43 & 32,57 & 79,28 & 20,72 \\
\hline & Canarias $^{29}$ & 78,31 & 21,69 & 82,52 & 17,48 \\
\hline \multirow[t]{2}{*}{$2003-2004$} & España & 67,49 & 32,51 & 80,87 & 19,30 \\
\hline & Canarias & 78,42 & 21,58 & 85,02 & 14,98 \\
\hline \multirow[t]{2}{*}{$2004-2005$} & España & 67,53 & 32,47 & 81,57 & 18,43 \\
\hline & Canarias & 78,26 & 21,74 & 86,41 & 13,59 \\
\hline
\end{tabular}

Fuente: elaboración propia con datos del MEC.

tros extranjeros, lo que es especialmente destacado en el caso de los europeos no comunitarios, en los americanos del norte y en los asiáticos, como refleja la tabla 8 .

Si comparamos la distribución del alumnado inmigrante con el autóctono entre centros públicos y privados, observamos que hay menos diferencias en la distribución del alumnado autóctono y extranjero entre centros públicos y privados en Canarias que en el resto de España (ver tabla 9). Podría pensarse

29. Los datos del ICEC (2005) para ese curso académico coinciden en la distribución del alumnado extranjero, pero no en la del alumnado total. En este último seguiría presente, según esta fuente, la misma tónica de los dos primeros cursos académicos señalados: mayor porcentaje de alumnado extranjero en centros privados que de alumnado autóctono. 
que ello es así porque el sistema educativo en el archipiélago es más igualitario, pero esa no parece ser la explicación, ¿o sí?

Aunque los datos de Estructura Social de Canarias no son muy recientes (1996) y la otra fuente estadística que nos aporta algunas cuestiones sobre las condiciones de vida de la población es de 2001, podemos encontrar algunas explicaciones en dicha estratificación. Ya antes, el censo de 1991 refleja que los canarios sólo son mayoría en ganadería, pesca, agricultura, como peones y trabajadores no especializados. En cambio, sobresalen en directores y gerentes los extranjeros, que multiplican en algo más de tres a los canarios. Los extranjeros son mayoría en el grupo de comerciantes y vendedores, puesto que superan el doble de la proporción de canarios (Zamora, 2003: 192) ${ }^{30}$.

Una situación que también refleja más recientemente la Estadística de condiciones sociales de la población canaria 2001 (ISTAC, 2001). Los canarios destacan en las profesiones descualificadas en primer lugar, seguido de trabajadores cualificados de la construcción, los hombres, y personal administrativo, las mujeres. Los inmigrantes de otra comunidad autónoma, en cambio, sobresalen en el grupo de profesionales y técnicos y trabajadores de restauración, mientras los inmigrantes extranjeros se mueven entre la primera profesión de los canarios y la segunda, de los llegados del resto de España, probablemente por las circunstancias tan distintas que representan los llegados del norte y los que lo hacen del sur. Además, los canarios son el colectivo que menos ingresos perciben, los inmigrantes del resto del Estado español los que más y, de nuevo en el caso de los extranjeros, se polariza la situación entre los ingresos más bajos y los más altos (Zamora, 2003: 193).

Todo lo cual nos ayuda a entender que en algunos cursos haya en Canarias mayor proporción de alumnado extranjero que de alumnado autóctono en centros privados (ver tabla 9).

Veamos brevemente cómo es la situación comparativa con las comunidades autónomas de mayor peso en inmigración. Tal y como hemos sintetizado en la tabla 10, Andalucía y Canarias son las comunidades donde se da mayor igualdad entre alumnado autóctono y extranjero, medida ésta en términos de acudir más equilibradamente a centros públicos o privados. Mientras estas dos comunidades autónomas se sitúan muy por debajo de la media española, ocurre lo contrario con Cataluña, Madrid y Valencia, que se convierten en las comunidades más desigualitarias a mucha distancia de la media.

Por tanto, han surgido algunas claves para entender el fenómeno de la inmigración en el archipiélago. Una, el mayor peso de la educación pública como indicador de la diferencia cultural, social y económica con la media española,

30. Dejamos de lado en este análisis al alumnado inmigrante peninsular por no disponer de información estadística sobre el mismo, aunque sería crucial, como decíamos al principio, poder contar con ella para un análisis más completo de la inmigración en el sistema educativo.

En cualquier caso, los peninsulares multiplican por dos a los canarios en directivos y gerentes y son mayoría en el grupo de profesionales y técnicos. En las fuerzas armadas, multiplican por algo más de ocho la representación canaria. 
Tabla 10. Alumnado autóctono e inmigrante según titularidad del centro y comunidad autónoma con mayor relevancia en alumnado extranjero. Curso 2004-2005

\begin{tabular}{|c|c|c|c|c|c|c|c|}
\hline & \multicolumn{2}{|c|}{$\begin{array}{l}\% \text { alumnado } \\
\text { extranjero }\end{array}$} & \multicolumn{2}{|c|}{$\begin{array}{l}\% \text { alumnado } \\
\text { total }\end{array}$} & \multirow[t]{2}{*}{$\begin{array}{l}\text { Diferencia } \\
\text { de puntos } \\
\text { porcentuales } \\
\text { alumnado } \\
\text { extranjero }\end{array}$} & \multirow[t]{2}{*}{$\begin{array}{l}\text { Diferencia } \\
\text { de puntos } \\
\text { porcentuales } \\
\text { alumnado } \\
\text { total }\end{array}$} & \multirow[t]{2}{*}{$\begin{array}{l}\text { Mayor } \\
\text { igualdad. } \\
\text { Relación } \\
\text { del alumnado } \\
\text { extranjero } \\
\text { con el total }\end{array}$} \\
\hline & Púb. & Priv. & Púb. & Priv. & & & \\
\hline Total & 81,6 & 18,4 & 67,6 & 32,4 & 63,2 & 35,2 & 28,0 \\
\hline Andalucía & 83,0 & 17,0 & 76,1 & 23,9 & 66,0 & 52,2 & 13,8 \\
\hline Canarias & 86,4 & 13,6 & 78,3 & 21,7 & 72,8 & 56,6 & 16,2 \\
\hline Cataluña & 84,1 & 15,9 & 60,3 & 39,7 & 68,2 & 20,6 & 47,6 \\
\hline Comunidad Valenciana & 86,0 & 14,0 & 68,4 & 31,6 & 72,0 & 36,8 & 35,2 \\
\hline Madrid & 74,6 & 25,4 & 55,2 & 44,8 & 49,2 & 10,4 & 38,8 \\
\hline
\end{tabular}

Fuente: elaboración propia a partir de datos del MEC. Datos definitivos, los otros son de avance.

independientemente de la inmigración. Dos, la mayor presencia de alumnado extranjero en educación privada respecto al autóctono hasta hace muy poco, a diferencia de lo ocurrido en el marco estatal ${ }^{31}$ y a pesar de contar éste con una proporción más elevada de centros privados. Tres, con una concentración mayor de inmigrantes en centros privados no concertados $(14,5 \%)$ que concertados (3\%), a la inversa de lo que ocurre con el alumnado autóctono $(6,5$ y $10 \%$, respectivamente $)^{32}$. Cuatro, en el archipiélago existen centros privados creados particularmente para satisfacer la demanda de una población extranjera acomodada, que albergan, en ocasiones, a más del 70\% del alumnado llegado del norte y recogen muchos centros a más de un $10 \%$ de su alumnado extranjero ${ }^{33}$. Cinco, cuando se habla de concentración, no se alude al tipo de sobrerrepre-

31. Como concluye el Consejo Económico y Social de Canarias: «En Canarias, y siguiendo la información del ICEC, las tres cuartas partes de los alumnos extranjeros están escolarizados en la enseñanza pública, lo cual no representa un desequilibrio cuantitativo en la medida en que la enseñanza pública escolariza más de los cuatro quintos del total de alumnos» (CES, 2003: 160).

32. Es decir, que en el curso 2002-2003, mientras que en los centros públicos hay un $94,1 \%$ de alumnado español y un 5,9\% de extranjero, en los centros privados no concertados esta distribución es de $86,8 \%$ y $13,2 \%$, respectivamente, y en los privados concertados, de un $98,2 \%$ y un $1,8 \%$ (ICEC, 2005). Las ratios en Canarias (alumnado extranjero por cada mil matriculados) son superiores a la media española en los centros privados.

33. Damos por supuesto que cuando se alude a lo negativo de una alta concentración de alumnado extranjero, que algunos cifran en superior al 30\% (Defensor del Pueblo, 2003: V-VI), no se está pensando en este colectivo.

No deben sorprendernos afirmaciones como las dadas por el consejero de Educación de Madrid negando que los centros con muchos inmigrantes sean peores, antes al contrario, se hallan calificaciones "muy por encima de la media" en dichos centros y algunos destacan por ser los más puntuados (El País, 1/7/2005). 
sentación constituida por los inmigrantes en centros concertados. Por tanto, no es que se hayan hecho bien los deberes de la integración, sino que se reciben inmigrantes de países ricos, que están abiertamente en contra de la integración, lo cual contribuye a la reproducción social.

Entre los centros educativos que albergan a un mayor número de alumnos extranjeros en las islas destaca un dato curioso. En Lanzarote, el centro de mayor concentración es privado no concertado, ubicado en Tías, recoge a un 59,27\% de alumnado extranjero, se llama Hispano Británico; el British School of Lanzarote situado en Teguise acoge a un 15,87\% de alumnado extranjero. En Gran Canaria, entre los siete primeros centros que cuentan con una mayor proporción de alumnado extranjero, cinco son privados no concertados: Escuela Noruega Gran Canaria, en Mogán, con un 95,38\% de extranjeros; Colegio Sueco Svenska Skolan, en San Bartolomé de Tirajana, con un 91,84\% de alumnado extranjero, y en el mismo municipio, con una concentración de un 47,06\%, está el English School of Gran Canaria; en la capital destacan dos con un porcentaje de alumnado extranjero importante, el British School of Gran Canaria $(41,71 \%)$ y el Norteamericano $(29,15 \%)$. Con una concentración alta, entre un 12 y un $20 \%$ la lista es mayor, entre ellos: Colegio Alemán, Oakley College, College Français, Alma’s o Kent College. Una tónica que se repite en Tenerife, los tres centros de mayor concentración de inmigrantes son privados no concertados: Colegio Adeje (97,22\%), English Educational Centre, en San Miguel (94,40\%), y Wingate School, en Arona (68,96\%). Y entre los siete primeros también está el Colegio Alemán $(41,25 \%)$ y el British Yeoward School (38,53\%), ambos en el Puerto de la Cruz. Y con más de un $20 \%$ de concentración de inmigrantes: Trinity School of English, en los Realejos; Colegio Alemán, en El Rosario, y Alexander Van Humboldt, en Adeje ICEC (2005: 19-25).

Sin embargo, de entre todos los centros con una concentración superior al $6 \%$ sólo son privados concertados, dos en Gran Canaria con 8,7\%, ambos en la capital, y dos en Tenerife, uno en Arona y otro en la capital.

¿Cuál es la lectura de estos datos? Por un lado, que los centros privados concertados no están matriculando alumnado extranjero en la misma proporción que el alumnado en general, que soportan más carga los centros públicos que los privados concertados, como mantiene el ICEC (2005: 29). Pero, por otro, que el alumnado extranjero en Canarias se concentre en altas proporciones en centros privados no concertados es un indicador del poder adquisitivo de sus familias. Lo que según zonas de procedencia se concreta en que de cada 10 alumnos extranjeros en centros privados no concertados, 6 son de la UE, 2 asiáticos y casi 2 europeos extracomunitarios. Y en centros privados concertados, la mitad son latinoamericanos, casi 3 de la UE y casi 2 asiáticos (ICEC, 2005).

En conclusión, el número de inmigrantes, su crecimiento, la relación entre el número de alumnado inmigrante y el autóctono, la distribución en los distintos niveles educativos y, sobre todo, entre centros públicos o privados, son algunos datos que nos permiten conocer mejor las características 
del alumnado inmigrante, el impacto para la comunidad de llegada y las similitudes o diferencias entre los diferentes espacios de Canarias y del resto de España.

Hemos demostrado que hay grandes desigualdades entre la población educativa inmigrante, lo que también se denota en la distribución de acuerdo con la titularidad del centro, que varía según comunidades autónomas, provincias, municipios, según el perfil social de la población extranjera ubicada en el territorio. Y, por ende, resulta difícil seguir manteniendo el discurso hegemónico sobre la concentración y la titularidad que propone, como hace el Informe del Defensor del Pueblo, intervenir para evitar la concentración, tomando medidas como la supervisión de los procesos de admisión de alumnos en centros concertados para que se cumpla la norma, introducir medidas preventivas para la admisión de alumnos, incluso limitar el derecho a la libre elección si fuera necesario, dando prioridad al derecho a la educación ${ }^{34}$ (Defensor del Pueblo (2003: VI-VII).

\section{Bibliografía}

Aja, E.; Larios, M. (2003). «Una visión jurídica». En: CONSEjo Escolar De Estado: Seminario 2003 Inmigración-Educación. Madrid.

AZURMENDI, M. (2003). «Inmigración y ciudadanía». En: Jornadas sobre Inmigración y Educación en la Comunidad de Madrid. Consejo Escolar de la Comunidad de Madrid.

BARÁIBAR, J. M. (2005). Inmigración, familias y escuela en educación infantil. MECCIDE.

BernsteIn, B. (1989). Clases, códigos y control. Madrid: Akal.

CARABAÑA, J. (2004). «La inmigración y la escuela». Revista Economistas, no 99. Colegio de Economistas de Madrid.

- (2006). «Una nueva ley de educación. De males inexistentes y remedios ineficaces». Claves de Razón Práctica, no 159.

CARbonell i París, F. (1997). «Entre la oveja Dolly y las reservas indias». Cuadernos de Pedagogía, 264.

CARBONELL, F. (2005). Educar en tiempos de incertidumbre. Equidad e interculturalidad en la escuela. Madrid: MEC.

CES (2003). Informe Anual 2003. Gobierno de Canarias.

- (2004). Informe Anual 2004. Gobierno de Canarias.

- (2005). Informe Anual 2005. Gobierno de Canarias.

CIDE (1992). Las desigualdades de la educación en España. Madrid: MEC.

- (1999). Las desigualdades de la educación en España, II. Madrid: MEC.

34. No debe perderse de vista que, como señalan Aja y Larios, el sentido original de la libertad de educación es el derecho que se da a los padres para elegir una educación no estatista, diferente a la creada por las autoridades públicas, es decir, a una educación privada, "pero no a que ello sea subvencionado por el Estado, pues ello no entra dentro del contenido prestacional del derecho a la educación». Por tanto, el derecho es a elegir una escuela privada frente a la financiada con recursos públicos. 
- (2003a). «El alumnado extranjero en el sistema educativo español (1991-2002)». Boletín CIDE de Temas Educativos, febrero, no 11.

- (2003b). «El alumnado extranjero en el sistema educativo español (1992-2003)». Boletín CIDE de Temas Educativos, diciembre, no 12.

- (2005a). «El alumnado extranjero en el sistema educativo español (1993-2004)». Boletin CIDE de Temas Educativos, enero, no 13.

- (2005b). «El alumnado extranjero en el sistema educativo español (1994-2005)». Boletín CIDE de Temas Educativos, junio, no 14.

Colectivo IOÉ (2003). La escolarización de hijas de familias inmigrantes. Madrid: CIDE.

CONSEJO ESCOLAR DE CANARIAS (2001). Multiculturalidad en los centros escolares de Canarias. Tenerife: Gobierno de Canarias.

DeFENSOR Del Pueblo (2003). Análisis descriptivo sobre condiciones de escolarización. Volumen I.

- (2003b). Estudio empirico sobre la situación educativa. Volumen II.

Díez, J.; RAMírez, M. (2001). La inmigración en España. Una década de investigaciones. Madrid: Ministerio de Trabajo y Asuntos Sociales.

Fernández Enguita, M. (2003). «La segunda generación ya está aquí». Papeles de Economía Española, no 98.

Fullana, J.; BesAlú, X.; VILÀ, M. (2003). Alumnes d'origen africà a l'escola. Girona: CCG Edicions.

Gobierno de Canarias (2001). Pacto social por la educación.

- (2005). Anteproyecto de Ley de Educación de Canarias.

HERNÁNDEZ i DOBON, F. J. (2004). «La "extranjerización" del alumnado de familia inmigrante en el sistema educativo, según la Ley de Calidad». Migraciones, $\mathrm{n}^{\circ} 15$, junio.

ICEC (2002). Borrador del anteproyecto para el estudio de "La multiculturalidad en la educación en Canarias». Gobierno de Canarias.

ICEC (2005). «Bases para la realización de un proyecto sobre inmigración, escolarización y educación multicultural en Canarias». <http://nti.educa.rcanaria.es/icec>.

- 2006). Nivel educativo del alumnado extranjero en curso 2004-2005, documento sin publicar.

INCE (2002). "Atención a la diversidad (2). Alumnado extranjero». Resumen Informativo, 10, marzo.

INE (2005). Encuesta de migraciones 2003. Madrid. <http://www.ine.es/inebase/cgi/axi>.

- (2006). Explotación estadística del padrón municipal a 1 de enero de 2005. Datos definitivos, 17 de enero de 2006.

ISTAC (2001). Condiciones sociales de la población canaria.

"Las matriculaciones de alumnos inmigrantes se estancan por primera vez en cinco años». El País, 26-9-2005.

MEC (2005a). Estadística de la educación en España, 2004-2005. <http://www.mec. es/mecd/estadisticas $>$. Datos estadísticos del alumnado extranjero.

- (2005b). Datos y cifras. Curso escolar 2005/2006.

- (2005c). Las cifras de la educación en España. Edición 2005. <http://www.mec.es/ mecd $>$. El alumnado extranjero.

NAVARro, J. L.; Huguet, A. (2005). El conocimiento de la lengua castellana en alumnado inmigrante escolarizado en $1^{\circ}$ de la ESO. Un estudio empirico. MEC-CIDE.

TERRÉN, E. (2001). «La conciencia de la diferencia étnica: identidad y distancia cultural en el discurso del profesorado». Papers, no 63/64.

- (2005). «Sociología de la educación, inmigración y diversidad cultural: panorámica de dos décadas». Tempora, $\mathrm{n}^{\circ} 8$. 
ZAMORA FORTUNY, B. (2003). «Inmigración y mercado de trabajo en Canarias. La construcción social del inmigrante». Inguruak, $\mathrm{n}^{\circ} 34$, diciembre.

- (2004). "Cultura, socialización e inmigración. Un estudio sobre la prensa en Canarias». Migratio: Revista de población y migraciones. <http://www.emigratio.com>.

- (2005). "Inmigrantes y educación: todos diferentes, todos desiguales». Tempora, número extraordinario. 